\title{
OBITUARY
}

\section{Harold Victor Forbes Jordaan}

Born in Cape Town on 14 April 1928, Harold passed away peacefully with his wife June next to his bed in Connecticut, USA, on 1 April 2013. In her loss, June is supported by her 2 children Micheline and Michael, who live relatively nearby with their families.

Harold graduated MB ChB from UCT in 1951 and went on to obtain his Master's in Obstetrics and Gynaecology in 1956. He was a man of exceptional intellect, which he demonstrated both in his achievements in the basic sciences related to his discipline, in his astute clinical practice, and in his non-medical interests in language and literature.

As a doctor in the apartheid era, he was subject to many restrictions. In the 1950s, Harold was only allowed to do his internship and training at Somerset Hospital. Even with his specialist qualification, there were significant strictures on where he was allowed to practise. He therefore did not practise as an obstetrician/gynaecologist specialist but served the community for many years as a general practitioner in Athlone. A career as an academic in an academic institution, which would have most suited his superior intellect, was also denied him.

Nevertheless, Harold was not deterred and proved his academic merit by obtaining a MD in 1957 from UCT; his thesis was entitled Persistent Occipito-Posterior Positions. As academic recognition still eluded him, he repeated this tour de force in 1973 by obtaining his $\mathrm{PhD}$ (UCT) on 'A study in Maternal Pelvic Capacity and Frontal Cranial Dimensions in the South African Negro and its Bearing on Human
Evolution'. His mentor was his beloved Professor Phillip Tobias. Harold was probably the only general practitioner in SA to have written 2 major theses and be awarded 2 doctoral degrees.

Despite being a 'specialist' for 13 years with a doctorate, he enrolled with the Royal College of Obstetrics and Gynaecology in 1973 and, together with much younger candidates, wrote the RCOG examination. The legend goes that he almost failed as he dared to debate the treatment of gynaecological tuberculosis with his examiner, who probably had far less experience with this condition than Harold.

He acted as part-time obstetric consultant to the old St Monica's Maternity Hospital (run by the Church of England to enable the training of black midwives in Cape Town), and it was there that many generations of budding O\&G specialists met him and fell under his spell. His knowledge of the scientific basis of $O \& G$ was legendary. It was early in the 1970s that the Part One (Science) examination was introduced for $O \& G$ specialisation and the registrars clamoured for tutorials in basic science. This Harold graciously provided, and the weekly basic science tutorial in his home will be fondly remembered by many established O\&G specialists. In addition, Harold and June opened their home to us on a regular basis when we could enjoy good food and culture; this included the Mexican tradition of drinking tequila!

However, even this good-natured man could no longer accept being denied joining the mainstream academic stream for ever, and so he eventually decided to emigrate to the USA in 1977. He first worked in Richmond, Virginia, and later transferred to Albany in New York State. Here he pursued his interest in fetal medicine, where he became an expert at complex scanning and invasive procedures. He received widespread recognition in the USA and became a senior member of the American Institute of Ultrasound in Medicine, a member of the New York Academy of Sciences, and an elected member of the American College of Obstetrics and Gynecology. He was also international editor of the Journal of Clinical Ultrasound. He published widely in the fields of obstetrics and physical anthropology.

His bond with South Africa never weakened, and he returned to SA in 1987 when, for the first time, he could practise as a specialist. During this time, he helped to build up the excellent services offered by the Fetal Medicine Unit in Groote Schuur Hospital.

Torn between South Africa and the fact that both his children decided to settle in the USA, Harold and June chose their children and returned to Albany in the USA during 1991. On retirement, they settled in Connecticut to be near their family, but visited SA regularly. One of his great joys was to sit on his small lawnmower tractor and mow the large lawns around his house. Those who were privileged to cross paths with Harold and to be blessed by his teaching and support will miss him terribly as he was our role model.

\section{E J Coetzee}

\section{J M Stewart}

Groote Schuur Hospital and Faculty of Health Sciences,

UCT

cstewart@global.co.za 